\title{
Efeito de alagamento e de aplicação de \\ fitorreguladores na brotação de Guazuma ulmifolia (Malvaceae) e de Sesbania virgata (Fabaceae) ${ }^{1}$
}

\author{
DANIELE GIANCRISTOFARO CORTEZI ${ }^{2,3}$ e SANDRA COLLI ${ }^{2}$
}

(recebido: 26 de agosto de 2010; aceito: 11 de agosto de 2011)

\begin{abstract}
Effect of flooding and application of plant growth regulators on sprouting of Guazuma ulmifolia (Malvaceae) and Sesbania virgata (Fabaceae)). Plants of Guazuma ulmifolia Lam. (4 month-old) and Sesbania virgata (Cav.) Pers. (2 month-old) were submitted to flooding in order to assess sprouting and elongation of the stem of these species, and to examine the effect of ethylene and kinetin in theses processes. The plants were submitted to flooding or maintained in dry soil for a period of 100 days and also together with: Ethrel, Ethrel with 6-BA, 6-BA or silver nitrate. Plants of G. ulmifolia sprouted after a short period of flooding, and the application of Ethrel and of Ethrel and 6-BA, in addition to the conditions of flooding, prompted the emergence of a greater number of branches than the other treatments. The application of silver nitrate, in flooded plants of G. ulmifolia, inhibited the development of lateral branches. In S. virgata, plants that received the application of 6BA, on substrate drained or flooded, had a larger number of branches than the other treatments. Plants of G. ulmifolia and S. virgata showed a decrease in stem elongation as lateral branches were formed. The two species showed different tolerance mechanisms that contributed to their survival under conditions of prolonged flooding.
\end{abstract}

Key words - 6-BA, branching, ethylene, hypoxia

RESUMO - (Efeito de alagamento e de aplicação de fitorreguladores na brotação de Guazuma ulmifolia (Malvaceae) e de Sesbania virgata (Fabaceae)). Plantas de Guazuma ulmifolia Lam. e Sesbania virgata (Cav.) Pers. com quatro e dois meses, respectivamente, foram submetidas ao alagamento com o objetivo de avaliar a brotação e o alongamento do caule destas duas espécies, e analisar o efeito do etileno e da citocinina nesses processos. Para isso, as plantas foram submetidas ao solo alagado ou mantidas em solo drenado por um período de 100 dias e também acrescido, em ambos os casos, de: Ethrel, Ethrel com 6-BA, 6-BA ou nitrato de prata. As plantas de G. ulmifolia apresentaram brotação após curto período de alagamento, e a aplicação de Ethrel e de Ethrel e 6-BA, somada às condições de alagamento, estimulou o surgimento de um maior número de ramos do que nos demais tratamentos. A aplicação de nitrato de prata, em plantas alagadas de G. ulmifolia, inibiu o desenvolvimento de ramos laterais. Em S. virgata, as plantas que receberam a aplicação de 6-BA, em substrato drenado ou alagado, apresentaram maior número de ramos do que nos demais tratamentos. Tanto as plantas de G. ulmifolia como as de $S$. virgata apresentaram diminuição no alongamento do caule à medida que ramos laterais foram formados. As duas espécies estudadas apresentaram diferentes mecanismos de tolerância que contribuíram para sua sobrevivência em condições de alagamento prolongado.

Palavras-chave - 6-BA, etileno, hipoxia, ramificação

\section{Introdução}

O alagamento é o maior determinante da vegetação em florestas ciliares (Visser et al. 2003). Consequentemente, grande parte dos vegetais não sobrevive por longos períodos nessa condição (Perata \& Alpi 1993). A baixa concentração de oxigênio no solo alagado pode promover mudanças bioquímicas, fisiológicas, anatômicas e morfológicas nas plantas (Armstrong et al. 1994), importantes para a redução

1. Parte da dissertação de mestrado da primeira autora, Programa de Pós-Graduação em Ciências Biológicas, Universidade Estadual de Londrina/UEL, Londrina, PR, Brasil.

2. Universidade Estadual de Londrina, Departamento de Biologia Animal e Vegetal, Centro de Ciências Biológicas, Caixa Postal 6001, 86051-990 Londrina, PR, Brasil.

3. Autor para correspondência: danicortezi@yahoo.com.br do impacto de estresse a que são submetidas (Visser et al. 2003), pois auxiliam a difusão do oxigênio para as raízes (Armstrong et al. 1994).

Mudanças no desenvolvimento das plantas durante o alagamento refletem alterações nos níveis hormonais (Armstrong et al. 1994), sendo que o etileno é o hormônio mais envolvido nas respostas que ocorrem em condições de alagamento (Vartapetian \& Jackson 1997).

O etileno é um hormônio gasoso formado a partir do ACC (ácido 1-aminociclopropano-1-carboxílico) acumulado nas raízes sob alagamento (Bradford \& Yang 1980). O ACC se difunde, por espaços intercelulares (Armstrong et al. 1994), para a parte aérea onde é convertido a etileno, devido à disponibilidade de oxigênio (Bradford \& Yang 1980), por ação da oxidase do ACC presente nas folhas de plantas alagadas (Else \& Jackson 1998). 
Em muitas espécies, o alagamento provoca modificações como a epinastia (Tsukahara \& Kolowski 1985, Pimenta et al. 1994), senescência precoce e abscisão das folhas (Serôdio \& Novais 1991, Marques et al. 1996), que são estimuladas a curta distância pelo etileno (Armstrong et al. 1994, Medri et al. 2002). Além dessas modificações, ocorrem também a redução de crescimento (Tsukahara \& Kolowski 1985, Marques et al. 1996, Kolb et al. 1998, Medri et al. 1998) e a hipertrofia da base do caule (Tsukahara \& Kolowski 1985, Yamamoto et al. 1995, Pimenta et al. 1996, Medri et al. 1998), que são respostas a longas distâncias estimuladas pelo etileno (Armstrong et al. 1994, Medri et al. 2002). Muitas espécies também formam estruturas que melhoram a troca de gases com o ambiente e a difusão interna do oxigênio, como a hipertrofia de lenticelas (Kolb et al. 1998, Schaffer 1998, Medri et al. 1998), a formação de rachaduras no caule (Pimenta et al. 1996, Davanso-Fabro et al. 1998), o desenvolvimento de raízes adventícias (Tsukahara \& Kolowski 1985, Yamamoto et al. 1995, Kolb et al. 1998) e a formação de aerênquima (Medri et al. 1998).

A aplicação de Ethrel (ácido-2-cloroetilfosfônico), um liberador de etileno, intensificou as respostas de epinastia (Pimenta et al. 1994, Davanso et al. 2003), hipertrofia das lenticelas (Pimenta et al. 1994, Medri et al. 1998, Davanso et al. 2003), aumento do diâmetro do caule (Pimenta et al. 1994, Davanso et al. 2003), redução do crescimento (Davanso et al. 2003) e aumento do número de raízes adventícias (Colli 1998) em plantas alagadas.

O aparecimento de ramos na base do caule foi observado em plantas alagadas, como Salix alaxensis (Anderss.) Cov., S. interior Rowlee e Populus balsamifera L. (Krasny et al. 1988), Alnus japonica (Thunb.) Steud. (Yamamoto et al. 1995) e Guazuma ulmifolia Lam. (R. C. Gonçalves 2006, comunicação pessoal), cujos ramos surgiram nas porções submersas do caule. O desenvolvimento desses ramos foi observado em duas espécies de Croton (Colli 1998) e em Tabebuia avellanedae Lor. ex Griseb. (Davanso et al. 2003), tanto em plantas alagadas ou não, quando tratadas com Ethrel.

Duas espécies de plantas encontradas em ambientes alagados, Guazuma ulmifolia e Sesbania virgata, foram selecionadas com o objetivo de avaliar o tipo de ramificação do caule quando alagadas, bem como o eventual envolvimento do etileno e da citocinina no processo de formação de ramos e no alongamento do caule. Para isso foram propostas as seguintes hipóteses: a) plantas alagadas de $S$. virgata, assim como as de
G. ulmifolia, formam ramos na base do caule; b) o desenvolvimento de ramos laterais na base do caule é influenciado pelo etileno.

\section{Material e métodos}

Foram selecionadas duas espécies para o estudo: Guazuma ulmifolia Lam. (Malvaceae) e Sesbania virgata (Cav.) Pers. (Fabaceae). Popularmente conhecida como mutambo, G. ulmifolia é uma espécie arbórea semidecídua, heliófita e pioneira, encontrada em quase todo o país, desde a Amazônia até o Paraná, principalmente na floresta latifoliada semidecídua (Lorenzi 2002). É uma espécie capaz de responder com alterações morfológicas ao estresse hídrico do alagamento, sendo, portanto, adaptada a ambientes hipóxicos (R. C. Gonçalves 2006, comunicação pessoal). Sesbania virgata, popularmente conhecida como cambaí, é uma espécie arbórea indicada à recomposição de áreas degradadas (Araujo et al. 2004), pioneira e de ocorrência nas regiões Centro-Oeste, Sudeste e Sul do Brasil (Pott \& Pott 1994). É uma espécie que apresenta modificações morfológicas e anatômicas em resposta ao alagamento, importantes para tolerar o estresse imposto pela deficiência de oxigênio (Davanso-Fabro et al. 1998).

As sementes de G. ulmifolia e $S$. virgata foram obtidas de frutos oriundos de diferentes indivíduos e beneficiadas no Labre (Laboratório de Biodiversidade e Restauração de Ecossistemas) da Universidade Estadual de Londrina. As plantas foram semeadas em tubetes e transferidas para vasos plásticos com aproximadamente quatro meses de idade no caso de G. ulmifolia, e dois meses para S. virgata. Vasos plásticos com capacidade para 3 litros, vedados no fundo para simulação de alagamento ou com furos, foram preenchidos com solo de barranco peneirado misturado com areia na proporção de 3:1 (Davanso et al. 2003) e as plantas aclimatadas em casa de vegetação por um período de 30 dias com o substrato mantido em condições de capacidade de campo (Davanso et al. 2003, Medri et al. 2007).

O experimento foi realizado nos meses de fevereiro a maio de 2007 e, no seu início, uma gema basal foi marcada por uma linha e a altura da parte aérea da planta foi aferida, tanto para G. ulmifolia quanto para S. virgata. Foram escolhidas plantas que apresentassem uniformidade na altura e no desenvolvimento e divididas em 10 grupos com nove repetições cada um. $\mathrm{O}$ alagamento foi feito preenchendo-se com água os vasos vedados no fundo. A água foi trocada de três em três dias, mantendo-se a lâmina de água a $3 \mathrm{~cm}$ acima da superfície de solo (Colli 1998).

A aplicação de fitorreguladores foi realizada com uma pipeta Pasteur em um algodão fixado na gema basal por um pequeno pedaço de fita-crepe. Conforme Colli (1998), a cada dois dias foram aplicados Ethrel (ácido-2-cloroetilfosfônico) na concentração de $20 \mathrm{mg} \mathrm{L}^{-1}$, 6-BA (6-benzilaminopurina) na concentração de $10^{-4} \mathrm{M}$, uma combinação de Ethrel e 6-BA, ou nitrato de prata (inibidor da ação do etileno, que 
também interfere na absorção de fósforo e na disponibilidade de ATP) na concentração de $5 \mathrm{mg} \mathrm{L}^{-1}$ (Colli 1998), totalizando 10 tratamentos como segue: (D) Drenado, controle; (A) Alagado; (DE) Drenado + Ethrel $\left(20 \mathrm{mg} \mathrm{L}^{-1}\right)$; (AE) Alagado + Ethrel (20 mg L-1 $)$; (DE6BA) Drenado + Ethrel $\left(20 \mathrm{mg} \mathrm{L}^{-1}\right)$ +6 -BA $\left(10^{-4} \mathrm{M}\right)$; (AE6BA) Alagado + Ethrel $\left(20 \mathrm{mg} \mathrm{L}^{-1}\right)+$ 6-BA $\left(10^{-4} \mathrm{M}\right)$; (D6BA) Drenado + 6-BA $\left(10^{-4} \mathrm{M}\right)$; (A6BA) Alagado $+6-\mathrm{BA}\left(10^{-4} \mathrm{M}\right) ;(\mathrm{DP})$ Drenado $+\mathrm{AgNO}_{3}\left(5 \mathrm{mg} \mathrm{L}^{-1}\right)$ e (AP) Alagado $+\operatorname{AgNO}_{3}\left(5 \mathrm{mg} \mathrm{L}^{-1}\right)$.

O experimento foi acompanhado ao longo de 100 dias com a finalidade de se registrar o início do aparecimento dos ramos. Ao final do experimento, foram avaliados o número de ramos formados e o incremento no alongamento do caule. $\mathrm{O}$ experimento foi montado em um delineamento inteiramente casualizado. Com o auxílio do programa SAS 8.0 (Silva et al. 2010), a análise estatística dos resultados apresentados foi realizada pela análise de variância (ANOVA) e as médias foram comparadas pelo teste de Tukey com nível de significância de $5 \%$, sendo que os dados do número de ramos e a porcentagem do incremento no alongamento do caule foram transformados para $\sqrt{x+0,5}$ para essa finalidade.

\section{Resultados}

Guazuma ulmifolia - O aparecimento de ramos basais em plantas alagadas (A) de G. ulmifolia ocorreu após nove dias em gemas da porção submersa do caule (figura 2). A partir do 6o dia do início do experimento, surgiram ramos a partir das diversas gemas localizadas na região submersa do caule em plantas dos tratamentos $\mathrm{AE}$ ou AE6BA, as quais apresentaram um maior número de ramos do que os demais tratamentos no final do experimento (figuras 3, 4 e 7A). A partir do 9 dia, os ramos começaram a aparecer em plantas do tratamento A6BA; do 12ํㅡㄹ dia, em DE6BA; do 21ํ dia, em DE e, do 39을 dia, em D6BA.

Esse experimento demonstrou que o alagamento somado à aplicação de Ethrel acelerou o processo de formação dos ramos, e que a aplicação de Ethrel e de 6-BA em plantas drenadas também estimulou a formação de ramos, porém, mais lentamente. As plantas dos tratamentos D (figuras 1 e 7A), DP e AP (figuras 6 e 7A) não apresentaram a formação de ramos.

O número de ramos basais em plantas de $G$. ulmifolia somente alagadas (A) foi baixo (figuras 2 e 7A). Resultados semelhantes foram observados em plantas do tratamento DE (figura 7A), DE6BA (figura 7A) e em A6BA (figuras 5 e 7A).

$\mathrm{O}$ incremento no alongamento do caule foi maior nas plantas de G. ulmifolia que não receberam a aplicação de fitorreguladores (D e A) e em plantas tratadas com D6BA, A6BA, DP e AP e foi menor em DE, AE, DE6BA e AE6BA, porém não diferiu das plantas somente drenadas (figura 7A).

Sesbania virgata - O aparecimento de ramos em plantas de $S$. virgata foi observado somente a partir das gemas que receberam aplicação de fitorreguladores em regiões não submersas na extensão do caule. Os mesmos surgiram apenas em plantas dos tratamentos DE6BA, AE6BA (figuras 7B e 11), D6BA e A6BA (figuras 7B e 12). Já, as plantas em condições $D$ (figuras $7 B$ e 8), A (figuras 7B e 9), DE, AE (figuras 7B e 10), DP e $\mathrm{AP}$ (figuras $7 \mathrm{~B}$ e 13) não apresentaram a formação de ramos no decorrer do experimento. $\mathrm{O}$ surgimento de ramos ocorreu a partir do $6^{\circ}$ dia em plantas do tratamento DE6BA, AE6BA e A6BA. A partir do 9o dia, em plantas do tratamento D6BA.

Na figura 7B podemos observar que o incremento no alongamento do caule foi menor nas plantas de $S$. virgata do tratamento D6BA, as quais também apresentaram um maior número de ramos em desenvolvimento na extensão do caule, juntamente com as do A6BA. Já o incremento no alongamento do caule foi maior nas plantas dos tratamentos D, A, DE, AE, DP, AP e em AE6BA. Essas plantas não apresentaram o surgimento de ramos na extensão caule, exceto as tratadas com AE6BA.

\section{Discussão}

A aplicação de Ethrel somada à possível síntese de etileno pelas plantas alagadas estimulou o desenvolvimento de um maior número de ramos em G. ulmifolia e, possivelmente, esse foi o motivo da diminuição do incremento no alongamento do caule. O efeito da aplicação de nitrato de prata, que inibiu o desenvolvimento de ramos em plantas alagadas, reforça a possibilidade do envolvimento do etileno no desenvolvimento dessas estruturas. Shimizu-Sato \& Mori (2001) consideram que a aplicação de fitorreguladores evidencia que os hormônios têm um importante papel na regulação de ramos axilares, pois a brotação depende da relação de auxinas e citocininas, sendo que as auxinas derivadas do ápice da parte aérea possuem um papel repressor/inibidor sobre o crescimento dos ramos laterais, enquanto as citocininas derivadas das raízes exercem um papel promotor. Esses autores também consideram que o aumento da produção de etileno nas plantas pode intensificar o processo de brotação.

Somente as plantas de $S$. virgata que foram tratadas com citocinina (6-BA) desenvolveram ramos a partir da gema selecionada, mostrando também um menor incremento no alongamento do caule. Segundo Medford 

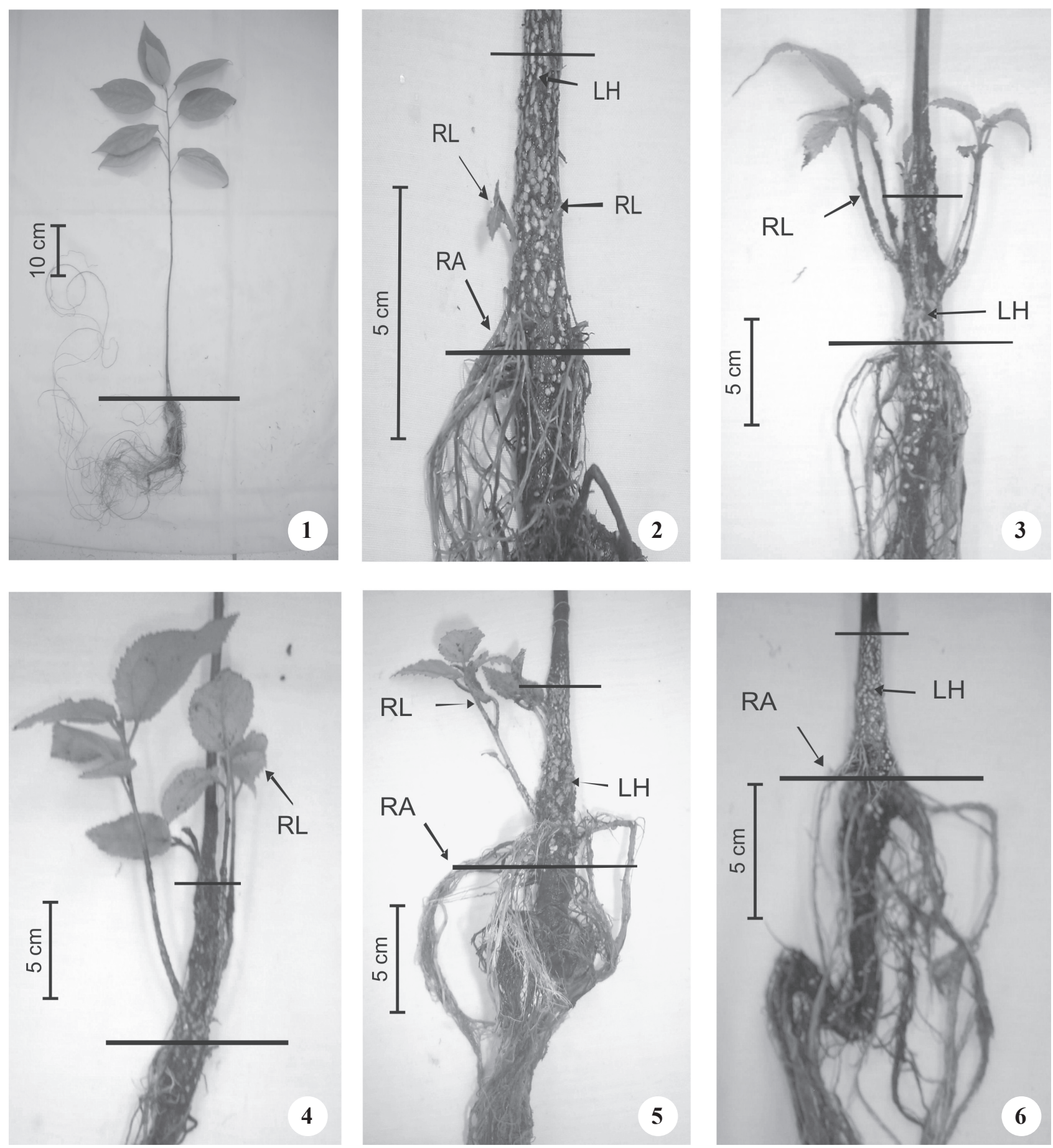

Figuras 1-6. Plantas de Guazuma ulmifolia após 100 dias submetidas ao alagamento e à aplicação de fitorreguladores. 1. Substrato drenado. 2. Detalhe de planta alagada. 3. Detalhe de planta alagada com aplicação de Ethrel. 4. Detalhe de planta alagada com aplicação de Ethrel e 6-BA. 5. Detalhe de planta alagada com aplicação de 6-BA. 6. Detalhe de planta alagada com aplicação de nitrato de prata. As setas indicam lenticelas hipertrofiadas (LH), ramo lateral (RL) e raiz adventícia (RA). As linhas horizontais indicam o nível do substrato (inferior) e da água (superior).

Figures 1-6. Plants of Guazuma ulmifolia after 100 days submitted to flooding and the application of plant growth regulators. 1. Drained substrate. 2. Detail of flooded plant. 3. Detail of flooded plant with application of Ethrel. 4. Detail of flooded plant with application of Ethrel and 6-BA. 5. Detail of flooded plant with application of 6-BA. 6. Detail of flooded plant with application of silver nitrate. Arrows indicate hypertrophied lenticels (LH), lateral branch (RL) and adventitious root (RA). The horizontal lines indicate the level of the substrate (below) and of the water (above). 

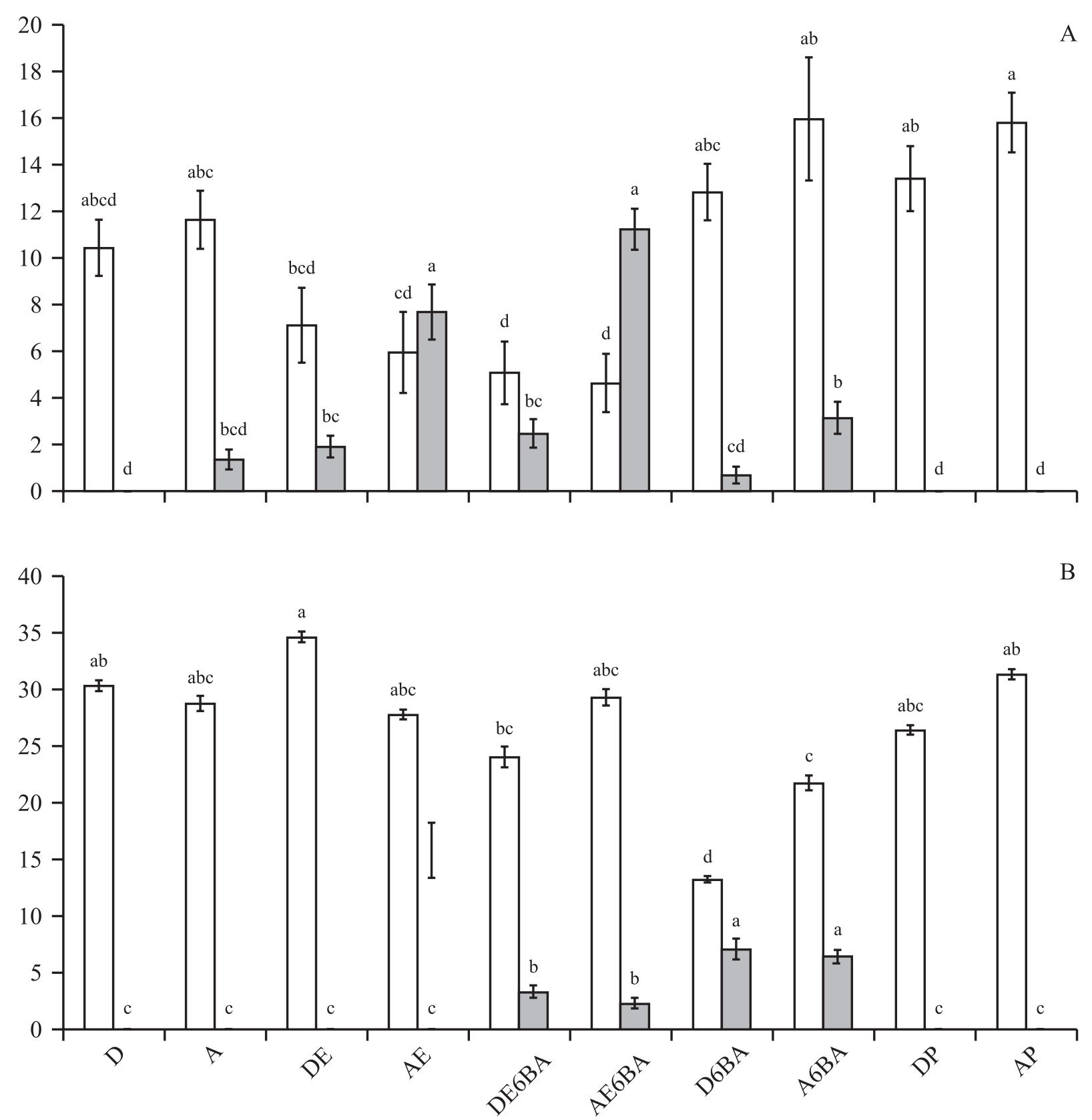

Figura 7. Incremento no alongamento do caule e média do número de ramos por planta de Guazuma ulmifolia (A) e Sesbania virgata (B) após 100 dias de tratamentos: drenado (D), alagado (A), drenado com aplicação de Ethrel (DE), alagado com aplicação de Ethrel (AE), drenado com aplicação de Ethrel e 6-BA (DE6BA), alagado com aplicação de Ethrel e 6-BA (AE6BA), drenado com aplicação de 6-BA (D6BA), alagado com aplicação de 6-BA (A6BA), drenado com aplicação de nitrato de prata (DP) e alagado com aplicação de nitrato de prata (AP) ( $\square=$ porcentagem do incremento no alongamento do caule; $\square=$ média do número de ramos). Dados seguidos de mesma letra, em cada caso, não diferem estatisticamente pelo teste de Tukey $(P<0,05)$, $n=9$. Os traços verticais acima das barras indicam o erro padrão das médias.

Figure 7. Increase in stem elongation and average number of branches per plant of Guazuma ulmifolia (A) and Sesbania virgata (B) after 100 days of treatments: drained (D), flooded (A), drained with application of Ethrel (DE), flooded with applications of Ethrel (AE), drained with application of Ethrel and 6-BA (DE6BA), flooded with applications of Ethrel and 6-BA (AE6BA), drained by application of 6-BA (D6BA), flooded with applications of 6-BA (A6BA), drained with application of silver nitrate (DP) and flooded with application of silver nitrate (AP). ( $\square=$ the percentage increase in stem elongation; $\square=$ average number of branches). Data followed by the same letter, in each case, not differ statistically by Tukey test $(P<0,05), n=9$. The vertical lines above the bars indicate the standard error. 

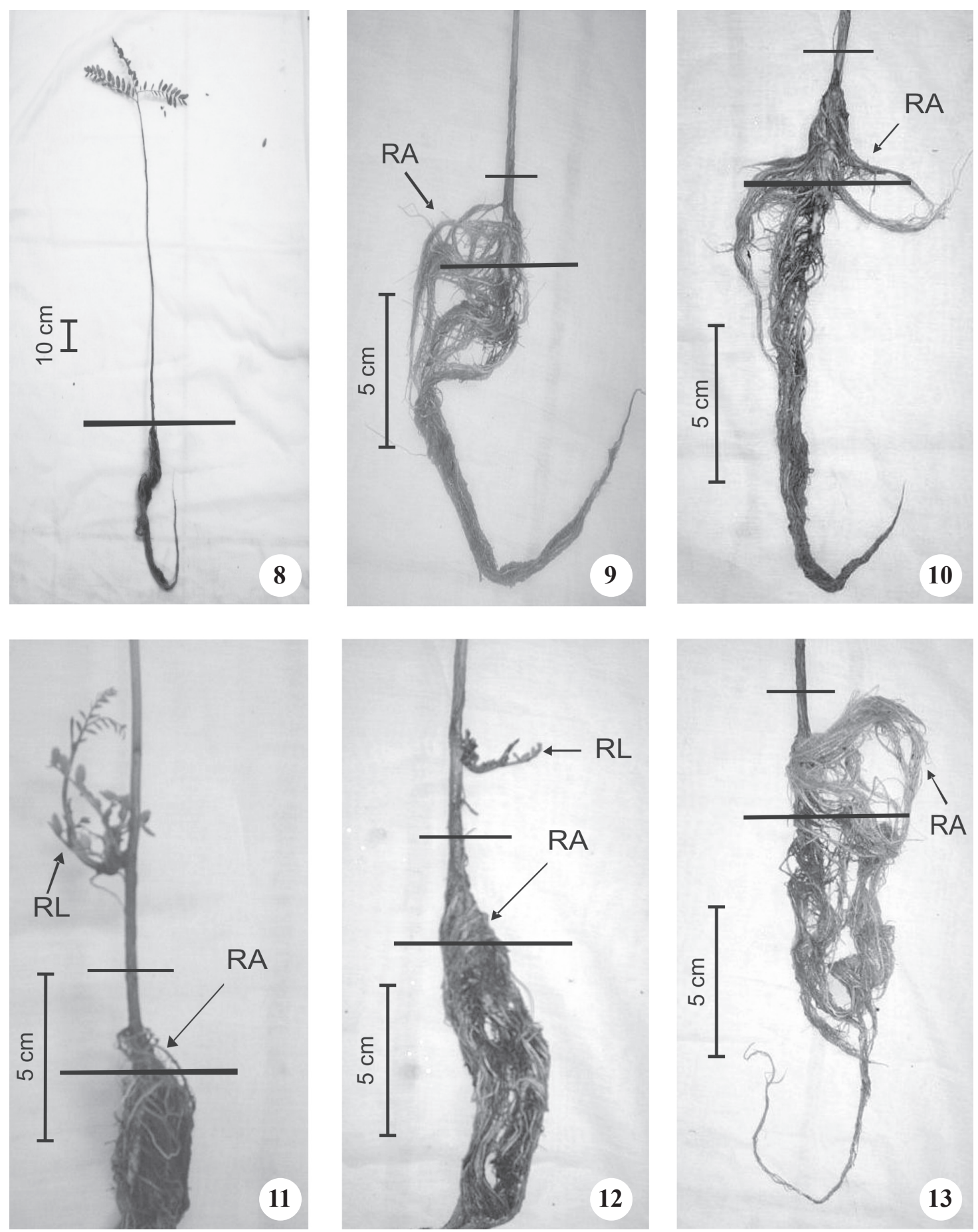

Figuras 8-13. Plantas de Sesbania virgata após 100 dias submetidas ao alagamento e à aplicação de fitorreguladores. 8. Drenado. 9. Detalhe de planta alagada. 10. Detalhe de planta alagada com aplicação de Ethrel. 11. Detalhe de planta alagada com aplicação de Ethrel e 6-BA. 12. Detalhe de planta alagada com aplicação de 6-BA. 13. Detalhe de planta alagada com aplicação de nitrato de prata. As setas indicam ramo lateral (RL) e raiz adventícia (RA). As linhas horizontais indicam o nível do substrato (abaixo) e da água (acima).

Figures 8-13. Sesbania virgata plants after 100 days submitted to flooding and the application of plant growth regulators. 8. Drained. 9. Detail of flooded plant. 10. Detail of flooded plant with application of Ethrel. 11. Detail of flooded plant with application of Ethrel and 6-BA. 12. Detail of flooded plant with application of 6-BA. 13. Detail of flooded plant with application of silver nitrate. Arrows indicate the lateral branch (RL) and adventitious root (RA). The horizontal lines indicate the level of the substrate (below) and of the water (above). 
et al. (1989), a aplicação direta de citocinina ou uma super expressão dos genes de biossíntese da citocinina podem induzir o crescimento dos ramos axilares.

Em S. virgata o desenvolvimento de ramos laterais em caules de plantas alagadas não ocorreu, possivelmente, porque essa espécie apresenta outras modificações morfo-anatômicas importantes para tolerar o alagamento, inclusive um maior crescimento das plantas alagadas do que as encontradas em solo drenado (Davanso-Fabro et al. 1998).

Baseado no estímulo do desenvolvimento de ramos laterais obtidos pela aplicação de Ethrel em plantas alagadas de G. ulmifolia e constatando os resultados obtidos por Haver et al. (2003), podemos sugerir que a formação desses ramos depende do efeito do etileno (endógeno e/ou exógeno) na diminuição da dominância apical e, também, do efeito direto que o etileno teria no desenvolvimento dos ramos laterais, possivelmente por alterar a relação auxina/citocinina. Essa hipótese estaria de acordo com duas das três sugestões propostas por Yamamoto et al. (1995) para explicar o desenvolvimento dos ramos laterais. Nesse caso, o etileno pode ter agido como um hormônio modulador na promoção do alongamento dos ramos na presença de citocinina, como foi observado por Harrison \& Kaufman (1982). Evidentemente, maiores estudos para comprovar essa hipótese são necessários, como as quantificações de teores de auxina e citocininas nas gemas laterais da base do caule, após a aplicação de Ethrel.

Em ambas as espécies estudadas, houve uma relação do incremento do caule com o número de ramos, pois à medida que o número de ramos aumentou, o incremento no alongamento do caule diminuiu. Segundo Yeang \& Hillman (1981), isso ocorre devido à inibição do crescimento apical, fazendo com que os nutrientes e outros fatores de crescimento sejam canalizados para os ramos laterais como se fosse um crescimento contrabalanceado.

Como conclusão do presente trabalho, verificou-se que ambas as espécies estudadas, G. ulmifolia e $S$. virgata, sobreviveram ao período de 100 dias de alagamento. Para G. ulmifolia, sugere-se que o etileno seria um importante modulador na formação de ramos laterais, especialmente demonstrado pela inibição do desenvolvimento desses ramos em plantas alagadas com a aplicação do nitrato de prata, e pela intensificação desse processo quando as plantas foram tratadas com Ethrel e 6-BA. O desenvolvimento dessas estruturas poderia ser considerado uma resposta morfológica que auxiliaria na tolerância ao alagamento prolongado. Já em S. virgata, a ramificação da base do caule observada tanto em plantas drenadas quanto alagadas foi especialmente influenciada pela citocinina, mostrando que as duas espécies apresentam distintos mecanismos que contribuem para a sobrevivência em condições de alagamento prolongado.

\section{Referências bibliográficas}

ARAUJO, E.C., MENDONÇA, A.V.R., BARROSO, D.G., LAMÔNICA, K.R. \& SILVA, R.F. 2004. Caracterização morfológica de frutos, sementes e plântulas de Sesbania virgata (Cav.) Pers. Revista Brasileira de Sementes 26:105-110.

ARMSTRONG, W., BRÄNDLE, R. \& JACKSON, M.B. 1994. Mechanisms of flood tolerance in plants. Acta Botanica Neerlandica 43:307-358.

BRADFORD, K.J. \& YANG, S.F. 1980. Xylem tranport of 1-aminocyclopropano-1-barboxylic acid an ethylene precursor in waterlogged tomato plants. Plant Physiology 65:322-326.

COLLI, S. 1998. Aspectos hormonais, anatômicos e do desenvolvimento de duas espécies de Croton submetidas ao alagamento. Tese de doutorado, Universidade de São Paulo, São Paulo.

DAVANSO, V.M., MEDRI, M.E., SOUZA, L.A. \& COLLI, S. 2003. Tabebuia avellanedae Lor. ex Griseb. (Bignoniaceae) submitted at the flooding and the "Ethrel" and silver nitrate application. Brazilian Archives of Biology and Technology 46:57-64.

DAVANSO-FABRO, V.M., MEDRI, M.E., BIANCHINI, E. \& PIMENTA, J.A. 1998. Tolerância à inundação: aspectos da anatomia ecológica e do desenvolvimento de Sesbania virgata (Cav.) Pers. (Fabaceae). Brazilian Archives of Biology and Technology 41:475-482.

ELSE, M.A. \& JACKSON, M.B. 1998. Transport of 1-aminocyclopropane-1-carboxilic acid (ACC) in the transpiration stream of tomato (Lycopersicon esculentum) in relation to foliar ethylene production and petiole epinasty. Australian Journal of Plant Physiology 25:453-458.

HARRISON, M.A. \& KAUFMAN, P.B. 1982. Does ethylene play a role in the release of lateral buds (tillers) from apical dominance in oats? Plant Physiology 70: 811-814.

HAVER, D.L., SCHUCH, U.K. \& LOVATT, C.J. 2003. Exposure of petunia seedlings to ethylene decreased apical dominance by reducing the ratio of auxin to cytokinin. Journal of Plant Growth Regulation 21: 459-468.

KOLB, R.M., MEDRI, M.E., BIANCHINI, B., PIMENTA, J.A., GILONI, P.C. \& CORREA, G.T. 1998. Anatomia ecológica de Sebastiania commersoniana (Baillon) Smith \& Downs (Euphorbiaceae) submetida ao alagamento. Revista Brasileira de Botânica 21:305-312. 
KRASNY, M.E., VOGT, K.A. \& ZASADA, J.C. 1988. Establishment of four Salicaceae species on river bars in interior Alaska. Holartic Ecology 11:210-219.

LORENZI, H. 2002. Árvores brasileiras: manual de identificação e cultivo de plantas arbóreas nativas do Brasil. vol. 1. Instituto Plantarum, São Paulo.

MARQUES, M.C.M., PIMENTA, J.A. \& COLLI, S. 1996. Aspectos do metabolismo e da morfologia de Cedrella fissilis Vell. e Anadenanthera colubrina (Vell.) Bren. submetidas a diferentes regimes hídricos. Brazilian Archives of Biology and Technology 39: 385-392.

MEDFORD, J.I., HORGAN, R., EL-SAWI, Z. \& KLEE, H.J. 1989. Alterations of endogenous cytokinins in transgenic plants using a chimeric isopentenyl transferase gene. Plant Cell 1:403-413.

MEDRI, M.E., BIANCHINI, E., PIMENTA, J.A., DELGADO, M.F. \& CORREA, G.T. 1998. Aspectos morfo-anatômicos e fisiológicos de Peltophorum dubium (Spr.) Taub. submetida ao alagamento e aplicação de Ethrel. Revista Brasileira de Botânica 21: 261-267.

MEDRI, M.E., BIANCHINI, E., PIMENTA, J.A., COLLI, S. \& MÜLLER, C. 2002. Estudos sobre tolerância ao alagamento em espécies arbóreas nativas da bacia do rio Tibagi. In A bacia do Rio Tibagi. (E. Bianchini, O.A. Shibatta \& J.A. Pimenta, eds.). MC Gráfica, Londrina, p.133-172.

MEDRI, M.E., FERREIRA, A.C., KOLB, R.M., BIANCHINI, E., PIMENTA, J.A., DAVANSO-FABRO, V.M. \& MEDRI, C. 2007. Alterações morfoanatômicas em plantas de Lithraea molleoides (Vell.) Engl. submetidas as alagamento. Acta Scientiarum Biological Sciences 29:15-22.

PERATA, P. \& ALPI, A. 1993. Plant responses to anaerobiosis. Plant Science 93:1-17.

PIMENTA, J.A., ORSI, M.M. \& MEDRI, M.E. 1994. Aspectos morfológicos e fisiológicos de Coleus blumei Benth. submetido à inundação e à aplicação de ethrel e cobalto. Revista Brasileira Biologia 53:427-433.
PIMENTA, J.A., MEDRI, M.E., BIANCHINI, E., MULLER, C., OKAMOTO, J.M., FRANCISCONI, L.M.J. \& CORREA, G.T. 1996. Aspectos da morfoanatomia e fisiologia de Jacaranda puberula Cham. (Bignoniaceae) em condições de hipoxia. Revista Brasileira de Botânica 19:215-220.

POTT, A. \& POTT, V. 1994. Plantas do Pantanal. EmbrapaSPL, Brasília.

SCHAFFER, B. 1998. Flooding responses and water-use efficiency of subtropical and tropical fruit trees in a environmentally-sensitive wetland. Annals of Botany 81:475-481.

SERÔDIO, M.I. \& NOVAIS, M.C. 1991. Nutrientes, fotossíntese e crescimento de trigo em condições de alagamento do solo. Revista Brasileira de Botânica 14:97-101.

SHIMIZU-SATO, S. \& MORI, H. 2001. Control of outgrowth and dormancy in axillary buds. Plant Physiology 127:1405-1413.

SILVA, D.C.G., CARVALHO, M.C.C.G., RUAS, P.M., RUAS, C.F. \& MEDRI, M.E. 2010. Evidence of ecotypic differentiation between populations of the tree species Parapiptadenia rigida due to flooding. Genetics and Molecular Research 9:797-810.

TSUKAHARA, H. \& KOLOWSKI, T.T. 1985. Importance of adventitious roots to growth of flooded Platanus occidentalis seedlings. Plant and Soil 88:123-132.

VARTAPETIAN, B.B. \& JACKSON, M.B. 1997. Plant adaptations to anaerobic stress. Annals of Botany 79:3-20.

VISSER, E.J.W., VOESENEK, L.A.C.J., VARTAPETIAN, B.B. \& JACKSON, M.B. 2003. Flooding and plant growth. Annals of Botany 91:107-109.

YAMAMOTO, F., SAKATA, T. \& TERAZAWA, K. 1995. Growth, morphology, stem anatomy, and ethylene production in flooded Alnus japonica seedlings. IAWA Journal 16:47-59.

YEANG, H.Y. \& HILLMAN, J.R. 1981. Control of lateral bud growth in Phaseolus vulgaris L. by ethylene in the apical shoot. Journal of Experimental Botany 32:395-404. 